\title{
ON THE PATHOLOGY
}

\section{U P U S E R Y T H M A T O U S.}

\author{
BY
}

GEORGE THIN, M.D.

(Received November 20th, 1874-Read January 12th, 1875.)

The diseased condition of the skin described by Hebra as Seborrhcea congestiva in 1845, and by Cazenave as Lupus erythematosus in 1853, had not escaped the notice of previous observers. But to Hebra belongs the merit of having first given snch a clear description of the distinctive appearances, as permits of its being easily separated from other diseases with which it is liable to be confounded. His adoption of Cazenave's designation, although doubtless not made without sufficient reason, has nevertheless had the inconvenience of causing a frequent confusion of this disease with certain forms of lupus vulgaris from which it is specifically distinct.

For a detailed account of the malady I refer to Neumann's 'Lehrbuch,' and to the exhaustive article by Kaposi, in Hebra's 'Textbook of Skin Diseases.' I shall here give only such a short sketch of its symptoms and course as is 
necessary to show their connection with the pathology with which this paper is more immediately concerned.

Small red spots which do not completely disappear under pressure by the finger, and which by their junction form erythematous patches having a circular border and of various sizes, constitute the primary feature of the disease. The patches so formed have a slightly raised reddened edge, and in the centre are either covered with greasy closely adhering scales or have a sunken puckered cicatricial appearance. On the face, which is by far its most frequent seat, and especially on the nose, the scaly masses when removed present the peculiarity of having on their adherent surface numerous projecting processes, which are moulds of the widened mouths of the sebaceous follicles, now seen interspersed over the congested surface.

The disease may last for months or years, sometimes making little progress, sometimes healing at one part and advancing at another, the skin after its disappearance appearing either normal or having the cicatricial aspect to which I have referred. It may defy all treatment, while the general health of the patient may at the same time be excellent. The affected spots on the scalp which are present in most instances become bald.

In the majority of cases there is little more to be described, the essential characteristics being, in fact, fairly included in three points by Cazenave, namely, in redness, wasting of the skin without ulceration, and the identity of its nature under different aspects.

It differs essentially from lupus vulgaris in the absence of ulceration, in its affecting people who are in the prime of life, rarely beginning until after the age of twenty, and in its characteristic general appearance.

There remains, however, a minority of cases in which another chapter must be added to complete the history. After the disease has lasted in the above-described chronic state for an indefinite time, it appears in the form of acute eruptions, and not only on the face, but simultaneously on many parts of the whole body. Hundreds of points may 
spring up on the trunk and extremities in a few days. Kaposi records three cases in which the eruption appeared suddenly in the form of hæmorrhagic vesicles like crops of herpes. The complications of these severer forms of the disease are erysipelas, adenitis, anemia, and fever ; its termination being frequently fatal to life.

The nature of the morbid processes in the skin which determine this singular group of symptoms is naturally a subject that has excited deep interest amongst dermatologists, and the investigations of Neumann, Geddings, and Kaposi on this point are of the first importance. Hebra, reasoning from the appearance of the distended and plugged ducts of the sebaceous follicles, had connected the disease with these glands, but did not make any microscopic investigations into its nature.

Before describing the alterations of the skin which I found in a case which I had the opportunity of observing, I will state shortly what was found by the authors whose names I have just mentioned.

Neumann, ${ }^{1}$ who first published on this subject, describes the changes as consisting of alteration of the form and relative size of the papillæ, cell infiltration of the corium, and changes in the sebaceous glands. The changes in the glands consisted in growth of connective tissue around their walls, and degeneration of the secreting cells.

Geddings ${ }^{2}$ examined skin which was taken from the back of a patient. In this woman knotty swellings in the subcutaneous tissue preceded the erythematous appearance on the skin, and this condition he considered to be the first stage of the disease. In the subcutaneous knotty swellings over which the skin seemed normal he found enlargement of the sebaceous glands caused by a swollen condition of the secreting cells. The vessels around the follicles were enlarged and distended with blood-corpuscles. The surrounding connective tissue seemed softened, and the spaces between the fibrillæ widened.

\footnotetext{
1 'Wien. Med. Wochenschrift,' 1863.

2 'Sitzungsb. d. k. k. Akad. d, Wișs.' 1868.
} 
In knotty swellings over which the skin was reddened, in addition to the appearances already noted, the capillaries in the papillæ were widened. When the diseased part was still nearer the surface and felt hard to the finger, in addition to the before-mentioned alterations of the sebaceous follicles and the surrounding connective tissue, the latter was thickly infiltrated with cells. At the stage in which crusts had formed the cell infiltration was so abundant that the various elements of the tissue could with difficulty be identified. In the stage of cicatrisation these cells were filled with fat-molecules and shrunk. He mentions also a slight cell-growth around the sweat-gland coil.

As the result of his observations he makes the inference that lupus erythematosus is a special form of inflammation of the skin which begins at the sebaceous follicles.

Kaposi ${ }^{1}$ examined the affected skin in one of the cases in which the acute eruption had taken the form of hæmorrhagic vesicles. He found that the hair and sebaceous follicles were only slightly affected, more decided pathological changes being found in and around the sweatglands.

The sweat-coil and duct were surrounded by abundant cell-infiltration; the cells of the duct were granular, and the duct itself blocked up and atrophied. Accordingly, he defines the disease as an inflammation that may take its departure either from the sebaceous follicles or the sweatducts.

In the spring of $1873 \mathrm{I}$ had an opportunity of seeing a man who died at Vienna, in the wards of Professor Hebra, of the marasmus that sometimes supervenes in cases of lupus erythematosus of long standing, simultaneously with acute eruptions on parts of the skin previously healthy. He had suffered from the disease for eight years, chiefly on the face and scalp. The day after his death I obtained a small piece of skin for the purpose of examination, and $I$ have Professor Hebra's kind permission to publish the results.

For a few weeks before the patient died, the eruption

1 'Archiv f. Derm. u. Syphilis,' 1872. 
had appeared in a very decided form on the dorsal surfaces of the first phalanx of the fingers and toes. On the toes it was beginning to spread from the dorsum to the interdigital surfaces, and in order to be able to examine a diseased part in the earliest stage I cut out a piece of skin from the first toe at the part where the dorsum passes into the interdigital portion of the integument. After hardening for about a week in a solution of chromic acid, thin vertical sections were cut and examined. What I found was as follows :

The capillaries of the papillæ were enormously distended and filled with red blood-corpuscles. In some papillæ this distension was so great that a capillary loop nearly filled a papilla of medium width. In different parts of the corium, similarly distended and filled capillaries were also seen. The veins were also distended and filled with blood. The arteries were empty. The abundant network of capillaries surrounding the sweat-glands were also greatly distended and filled with blood-corpuscles.

The rete Malpighii, fibrillary tissue of the corium, and sweat-glands were perfectly healthy. I had cut so far beyond the region of the sebaceous glands, which, as is known, are here limited to the dorsal surface, that although I examined all the sections made from the portion of skin, in only one of them was there a hair and sebaceous follicle, and the gland was normal in appearance.

In regard to the sweat-glands of this part of the body I may mention that they are of a very large size, proportionate to the abundant secretion of sweat that takes place between the toes, and in some of the sections made from this man's toe the single layer of smooth muscular fibres that surround the larger sweat-coils were distinctly seen, and were also normal in appearance and development.

The importance of these facts when compared with those related by Neumann, Geddings, and Kaposi, and with the inferences they have made from them, is chiefly of a negative kind.

The great width and unbroken lumen of the capil- 
laries of the papillary layer indicate a congestion of some standing, and yet the fibrillary tissue and secreting structures of the skin were unaltered in appearance. Whatever possible cell-infiltration existed was not such as was indicated by staining with carmine. The disease was thus firmly established in a part of the skin where there are no sebaceous glands, and in which the sweat-glands still presented a normal appearance.

But although none of the changes that have been described by the authors above named as occurring in the sebaceous and sweat-glands and fibrillary tissue were present, there was a morbid condition of the capillary blood-vessels which, if it had been persistent, was certain, in course of time, to have produced all of them. This morbid condition was naturally most apparent where the supply of capillaries in the skin is greatest, namely, in the papillæ and around the sweat-glands.

An atrophied condition of the papillary layer of the cutis -what Cazenave has described as a thinning of the skinmust be the inevitable consequence of a prolonged stasis by which the circulation is virtually destroyed.

The conclusion to which these results naturally lead is, that as yet we know in this disease no changes antecedent to the congestion of the capillaries, and can associate it with no special constituent organs of the skin. This conception of its nature seems to me to be especially consistent with the history of cases of acute eruption, and more especially with those in which the eruption consists of hæmorrhagic vesicles. I would suggest, therefore, that the affections of the sebaceous and sweat-glands should be considered, not as being necessarily the causes of the congestion, but as following it. A fuller investigation into the pathological anatomy of the disease is, however, urgently needed.

Without entering on the question of remedies I may point out, in conclusion, merely, that as the primary stage is coincident with distension of the capillaries, the promising treatment introduced by Dr. Veiel, consisting in puncturing the whole of the erythematous surface with an instrument com- 
ON THE PATHOLOGY OF LUPUS ERYTHEMATOSUS. 65

posed of a number of closely apposed lancets, is at least a rational one.

The accompanying drawing was made by Mr. Ewart from one of the sections preserved in Dammar varnish. The fat vesicles at the lower edge haye been slightly displaced in order to limit the size of the drawing. 


\section{DESCRIPTION OF PLATE I.}

A. Lower part of the horny layer of the epidermis.

B. Rete Malpighi.

c. Distended capillary of a papilla (blood-corpuscles).

D. Artery.

E. Distended capillary in the corium (blood-corpuscles).

F. Fat.

G. Section of sweat coil.

H. Distended capillary in sweat coil (blood-corpuscles). 
Plate I.

Med. Chir. Trans. Vol. IVIII.

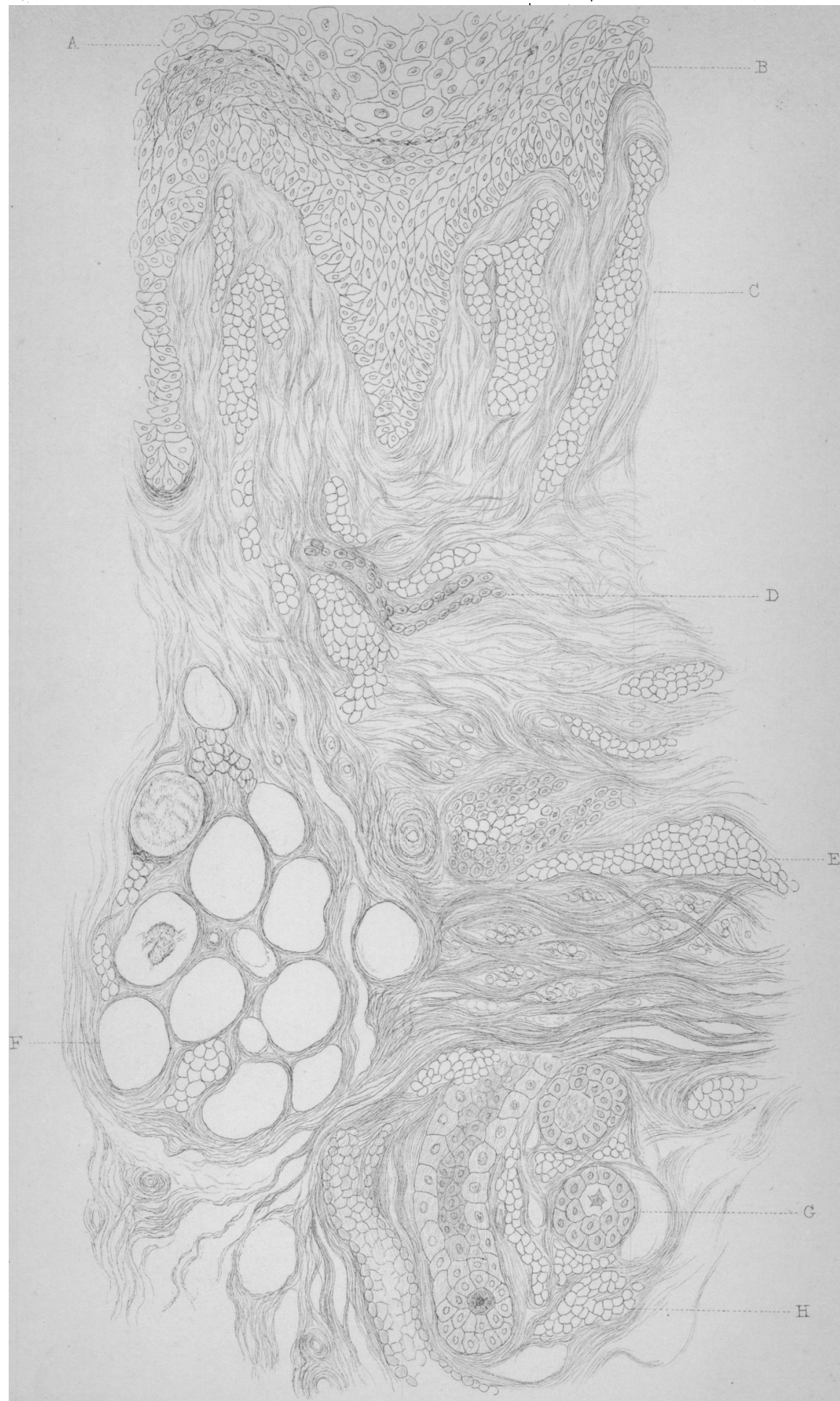

